\title{
Development and validation of analytic and holistic rubric guides in assessing concept cartoons
}

Randel D. Estacio ${ }^{a^{*}}$,

$\mathrm{R}$

$\mathrm{R}$

Suggested Citation:

New Trends and Issues Proceedings on Humanities and Social Sciences.

$\mathrm{R}$

Abstract

$\mathrm{R}$ 
Trends and Issues Proceedings on Humanities and Social Sciences.

1. Introduction

R I

I

$\mathrm{R}$

I

I 
Trends and Issues Proceedings on Humanities and Social Sciences.

\section{Methodology}

$\mathrm{R}$

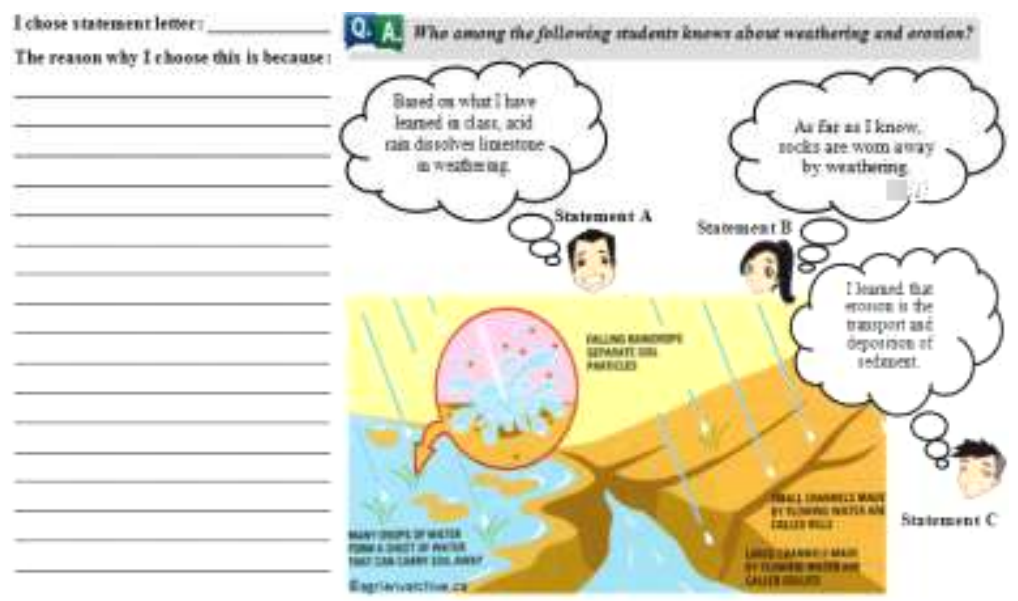

Figure 1. Concept Cartoon with Three Options

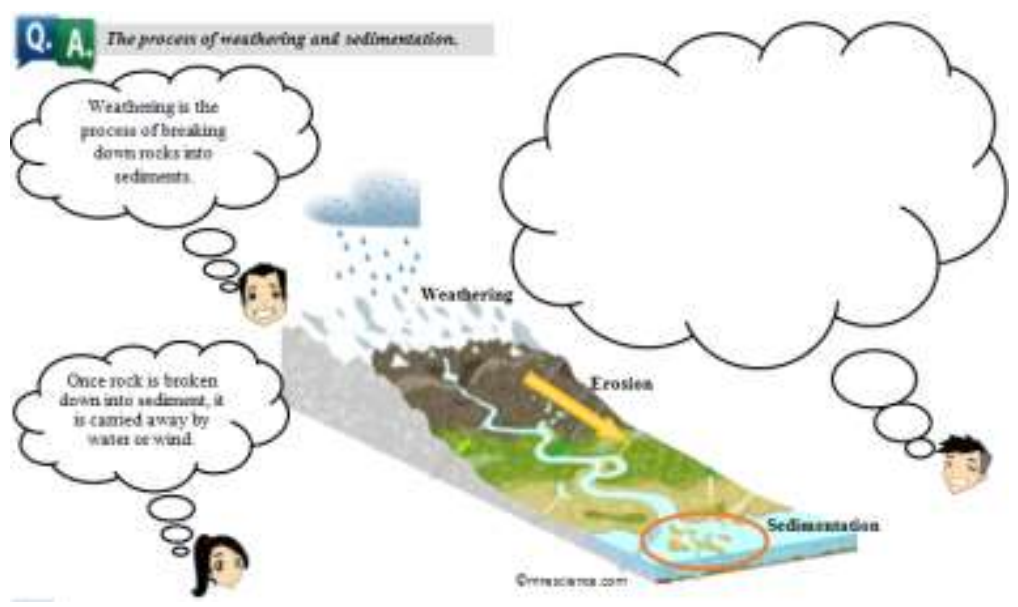

Figure 2. Concept Cartoon with One Empty Speech Bubble 


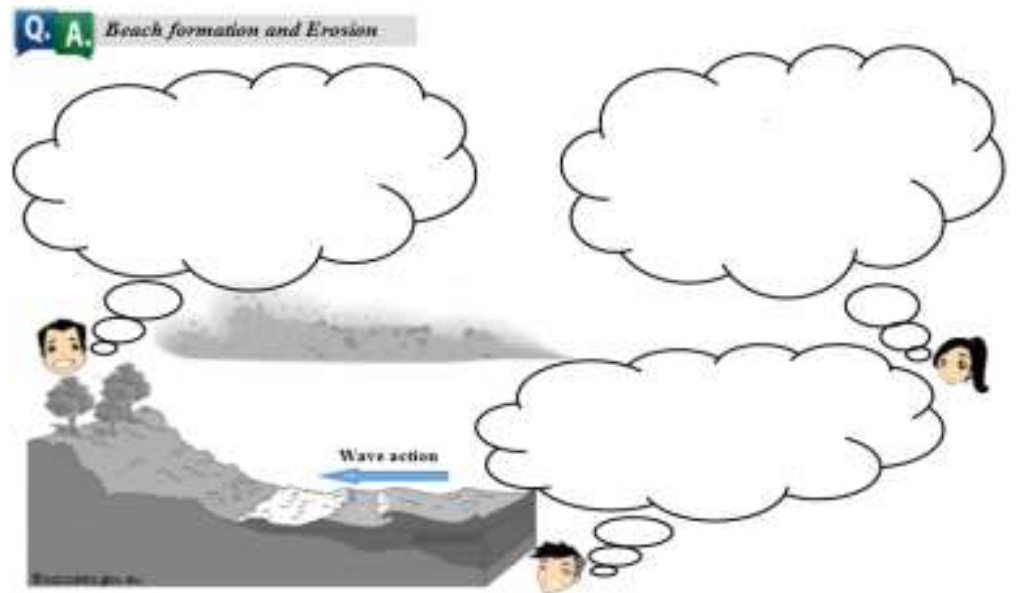

Figure 3. Concept Cartoon with Three Empty Speech Bubbles

3. Results and Discussion 
Table 3. Content validity coefficient of the third version of the analytic and holistic rubric guides

I 1


Table 4. Inter-rater reliability test

I

I

$\mathrm{R}$

Table 5. Internal consistency reliability test 


\section{Conclusion and Recommendations}

\section{References}

Psychological Measurement, 45

Educational and Procedia-Social and Behavioral Sciences, 1

$\mathrm{R}$ Middle East Journal of Scientific Research, 5 $\mathrm{R}$ I

Procedia - Social and Behavioral Sciences, 116,

International Journal of Science Education, 31(

International Journal of Environmental \& Science Education, 2

and Research in a Changing Planet

Biology Education

International Journal of Science Education,

Procedia - Social and Behavioral Sciences, 93,

Educational Sciences: Theory and Practice, 5

Procedia - Social and Behavioral Sciences, 116

Journal of Science Education, 21

International

Education, 33

I 1

Procedia Social and Behavioral Sciences 7,

English Journal 95

scientific investigations

The use of Concept Cartoons and Prompt Sheets in supporting learners in the planning of

Language Testing 19

Phi Delta Kappan 80

Educate Journal, 7

The Manila Journal of Science, 7 
Trends and Issues Proceedings on Humanities and Social Sciences.

$\mathrm{R}$

10

Assessment of learning outcomes (assessment 1).

Journal of Turkish Science Education,

$\mathrm{R}$

I

Chemical Engineering Education 36

Journal of Experimental Education 68

Eurasian Journal of Physics and Chemistry Education, 1

Procedia Social and Behavioral Sciences, 2,

Shaping the future of mathematics education: Proceedings of the 33rd annual conference of the Mathematics Education Research Group of Australasia.

English Journal 96

Effective Teaching, 7

The Journal of

Assessing Writing 4 